OPEN ACCESS

\title{
On Clusters: External and Internal Perspectives
}

\author{
Ifor Ffowcs-Williams
}

'There are few economic development policies as popular as clusters. It is hard today to find a country, region or even city that is not trying to develop a network of complementary and competitive firms.'(Economist Intelligence Unit 2011)

This paper examines the phenomenon of local clusters in two dimensions. Firstly an external perspective on clusters is taken, the origins of clusters identified and their significance for economic development highlighted. Secondly, the paper takes an inside look at clusters, exploring the key factors that lead to the success of strong, high performance clusters.

\section{CLUSTERS: AN EXTERNAL PERSPECTIVE}

Silicon Valley and Hollywood are two Californian clusters that have become household names. Both have naturally grown over decades from small beginnings. Such clusters are to be found in all corners of the world and across all sectors. In Europe some 10,000 clusters have been identified covering primary industries, secondary and tertiary. Many of these clusters in Europe and elsewhere have over time developed the competitiveness to establish a global reach though they may only familiar to industry insiders:

- Aarhus, Denmark: 'Capital of Wind Energy' and home to $87 \%$ of Denmark's wind industry;

- Bresle, France: 'Glass Valley' manufacturing 75\% of the world's perfume bottles;

- Costa Brava, Spain: supplies 70\% of the world's

*Correspondence to : Ifor Ffowcs-Williams

Ifor Ffowcs-Williams is the CEO of Cluster Navigators Ltd, a New Zealand based economic development consultancy that is active in 45 countries. Ifor is a founder and past president of The Competitiveness Institute (Barcelona), the leading global network for economic development practitioners addressing competitiveness in regions and clusters. This paper draws on a forthcoming 'Cluster Development Handbook'.

E-mail : e4@clusternavigators.com

World Technopolis Review

Copyright $\odot$ World Technopolis Association

CC This is an open-access article distributed under the terms of the Creative Commons Attribution Non-Commercial License(http://creativecommons.org/licenses/by-nc/3.0) which permits unrestricted noncommercial use, distribution, and reproduction in any medium, provided the original work is properly cited corks for sparkling wines;

- Hangji, China (population 35,000) produces 30\% of the world's toothbrushes;

- Montebelluna, Italy: 'Sports Footwear Capital of the World' (population 25,000) accounting for $75 \%$ of world ski boot production;

- Qiaotou, producing 80\% of China's buttons and $60 \%$ of global production;

- Stoke-on-Trent, UK and Limoges, France: two leading fine china production centers.

- Wenzhou, China: 95\% of the world's output of cigarette lighters.

Other clusters are more regional in their competitive scope, for example:

- Cape Town, South Africa: produces $45 \%$ of the country's clothing;

- Lyon, France: home to 70\% of French video game developers;

- Vallés Occidental County produces $80 \%$ of Spain's woolen fabrics;

- Sleman is known as 'Indonesia's City of Education' with 35 public and private universities. Similarly, Jyväskylä is known as Finland's 'City of Education,' This is a city where every fourth person is a student.

Some of these clusters are long established and have been 
able to continually re-invent themselves over the years. Many of the 6,000 clusters that have been identified in India have been in existence for centuries, including knitwear in Ludhiana and cotton in Tirupur, accounting for over half of India's cotton knitwear exports. A much more recent arrival in India is Bangalore's software cluster, accounting for onethird of India's IT exports.

\section{A Historic Perspective}

Clusters are in no way a new occurrence. The practice of businesses co-locating with related firms, even competitors, was observed in ancient Athens where food suppliers and jewellery retailers clustered in adjacent corners of the city's main market, the Agora.

Observers of this phenomenon include:

Alfred Marshall who described in 1890 'the Concentration of Specialised Industries in Particular Localities,' drawing on his observations in northern England: 'When an industry has chosen a locality for itself it is likely to stay there long: so great are the advantages which people following the same skilled trade get from near neighbourhood to one another... and presently subsidiary trade grows up in the neighbourhood' (Marshall 1890). Marshall described the advantages of being located in a cluster as the availability of skilled labour and intermediate goods and the easy transmission and discussion of new ideas and improvements.

Joseph Schumpeter in 1939 referred to the 'swarm like appearance of entrepreneurs' and 'the clustering of industry'(Schumpeter 1982).

Giacomo Becattini drew in 1979 on his experiences with Italy's industrial districts to highlight the importance of placecentered economic development and social relationships. Becattini highlighted passive 'embeddedness' and the active 'sense of belonging' to a place with a common vision.

Michael Porter in 1990 popularised the relevance of clusters as a framework for economic development with his seminal contribution (Porter 1998) drawing on the research that had been led by Michael Enright. This explored the reasons why some firms and some regions were particularly successful. Porter's comprehensive work centered on ten countries: Denmark, Germany, Italy, Japan, Korea, Singapore, Sweden, Switzerland, the UK and the US. The eleventh country Porter and his team investigated was New
Zealand with Michael Enright again leading the fieldwork (Crocombe et al 1991).

I was one of the many who visited Italy in the 80's and 90's and came away from these visits intrigued by the 'flexible specialisation' that Piore and Sabel(1984) had highlighted. Based on this learning a business-networking programme was developed in Denmark, closely followed by similar programmes in Canada, Norway, Australia, New Zealand and Oregon. In New Zealand the programme to encourage collaboration amongst small groups of SMEs was known as 'Hard Business Networks' to differentiate these formal commercial alliances (including consortiums and joint ventures) from softer networks such as industry associations and chambers of commerce. In New Zealand and other countries these programmes were precursors to the cluster development programmes that subsequently evolved.

\section{The Origins of Clusters}

Clusters by and large evolve serendipitously. Public policies support rather than create a cluster. Very few successful clusters around the world have been 'invented' by public agencies. No government has decreed that Hollywood should be the world's entertainment capital or that Silicon Valley should become the pre-eminent hi-tech cluster globally. While clusters are with very few exceptions a natural occurrence, the origins of clusters differ markedly. There is no single cause. Some examples:

Proximity to a natural resource, a raw material:

- Fishing/seafood: Reykjavik, Iceland; Humber, UK; Nelson, New Zealand; Lake Victoria, Uganda

- Mining services: Sudbury, Canada; Kalgoorlie, Australia

- Oil \& gas engineering: Houston, Texas; Calgary, Canada; Stavanger, Norway; Taranaki, New Zealand

- Udine, Italy's chair cluster, was in a forestry region

-Wine: Bordeaux and Burgundy, France; Barossa Valley, South Australia; Napa Valley, California; Marlborough, New Zealand

\section{Proximity to physical features:}

- Auckland, New Zealand's 'City of Sails' and super yacht manufacturing centre is centered on one of the world's most extensive harbours

- Beach tourism: Hawaii; Costa del Sol, Spain; Sunshine Coast, Queensland, Australia and Sunshine Coast, Eastern Cape, South Africa 


\section{Special Contribution}

A specific local demand, venturesome consumers:

- Beer drinkers in Portland, Oregon are five times more likely to drink beer from a microbrewery than the typical US consumer; Portland commuters are seven times more likely to commute by bike; and more likely to demand active footwear (leading to Portland being the home of Nike, Adidas North America and Columbia) ${ }^{1}$

- Manitoba, Canada has its niche in global aerospace as the world's leading cold weather testing location

- Reykjavik, Iceland is an exporter of cold-proof, soft terrain vehicles thanks to the local demand for glacierclimbing SUVS

- Sliedrecht, Netherlands is the world's leading dredging cluster, thanks to the local demand for precision dredging services

An external shock, adversity:

- The closure of a Fiat factory in Moderna, Italy in the 1950's stimulating the establishment of a number of firms including Bugatti, Ferrari, Lamborghini and Maserati.

- The closure of a steel works in Newcastle, Australia driving the growth of an engineering cluster, Hunternet.

Ethnic concentrations:

- Geneva, Switzerland watch cluster, with its origins in Protestant Hugenots escaping from persecution in France and Italy

- Moncton, New Brunswick: a major Canadian centre for translation services and bilingual PR \& marketing firms, thanks to the community's 50\% French and 50\% English composition

- Ultra-Orthodox Jewish diamond merchants in Manhattan, New York and Amsterdam

Cultural traditions, local history:

- Jazz, New Orleans

- Reggae music, Jamaica

- Basketry, Luwero, Uganda

Transport routes:

- Transport/logistics clusters in Rotterdam, Hong Kong, Singapore, Dubai and New Orleans

- Nigeria's Nnewi automotive components cluster is centred on a traditional trading and transport hub

Local anchors and public sector procurement
- Gothenburg's biotech cluster is centered on northern Europe's largest hospital, Sahlgrenska University Hospital

- Omaha, Nebraska's telemarketing cluster developed around the bandwidth installed for the local US Strategic Air Command facility

- Ottawa, Canada's high tech cluster has it's origins in a major government R \& D telecommunications laboratory, Bell Northern Research

Emerging from an existing cluster:

- Medical technology cluster, Saint-Etienne, France emerged from a historic textile cluster and then medical textiles.

- Mobile phone technology, North Jutland, Denmark emerged from maritime radio communications.

- Subsea Technology Cluster, North East England developed from a local heavy engineering tradition.

- Beijing's Zhongguancun Science Park, China's Silicon Valley, emerged in the mid 1980's from a cluster of computer retailers and is today home to many of China's leading IT companies, some 6,000 high tech SMEs, 39 universities and 213 research institutes.

- Medical instruments, Minneapolis, USA emerged from a declining computer industry.

Go-getting godfathers ${ }^{2}$ :

- Hyderabad IT, India: Chandrababu Naidu

- Oita, Japan's ‘Silicon City’: Morihiko Hiramatsu

- Silicon Valley, California: Frederick Terman

By chance:

- ICT in Seattle, Bill Gates' birthplace.

- Christchurch, New Zealand's electronics cluster is centered on Tait Electronics Ltd. whose founder moved to the city in 1945.

A deliberate intervention by a public agency:

- Hsinchu Science Park, Taiwan is frequently referred to as one of the few success stories of a government 'creating' a cluster following a visit by Taiwanese authorities to Silicon Valley in the 1970's. Growth was stimulated by encouraging the return of Taiwanese engineers with technical and management skills, by the provision of finance and ongoing connections to Silicon Valley. A go-getting godfather, Morris Chang,

\footnotetext{
1 Joe Cortwright, Portland, Oregon.

2 This category draws on Prof. Fred Phillips, State University of New York
} 
played a key role in the cluster's development.

- Austria's Hagenberg IT cluster has developed over 30 years from a university IT centre, now with a Software Park housing 60 firms including 30 start-ups. Public investment to-date has been Euros 120 million.

- The textile cluster in Mauritius began as an Export Processing Zone with special incentives.

\section{Why are Clusters Important?}

Why is this natural phenomenon of businesses clustering important as a framework for economic development? An answer lies in the positive relationship between strong clusters in a region and GDP per capita, in business growth and in new job creation.

Employment within any regional economy can be divided into two broad categories:

- Employment that is primarily centered on servicing the local economy, such as health care, teachers, vehicle repair, house building, hairdressing and retail. In many developed economies some two thirds, possibly three quarters, of jobs typically relate to servicing the local economy.

- Employment that is attracting wealth into the local economy through firms that are servicing customers in more distant markets. These firms are supplying products or providing services including tourism services, to customers in/from other regions. The customers may be in neighbouring regions or further afield in international markets. Typically a quarter, at times a third or even more of the local jobs are in this category.

It is most unlikely that a region will have a totally random collection of firms with the competitiveness to service more distant markets. Some pattern to the activity of most of these firms will have evolved over time. The firms could be clustered around a raw material, an anchor firm, a local knowledge centre, a common technology platform or a local skill. It is this traded side of a local economy, where there already is the competitiveness to service more distant customers, that is a key when it comes to local economic development.

From a firm perspective, the international evidence is now clear: firms that are based in clusters are more competitive than similar firms located outside the cluster, the firms that may be scattered around a country. Factors driving this enhanced competitiveness include the local availability of specialised inputs, specialised skills and a specialised infrastructure. Contrasting the domestic and the export-oriented firms, it is the export firms that exhibit higher productivity, higher levels of innovation, more new technical developments and more patent applications. It is on this side of the economy that more start-up firms are found; there are more firm spin-offs and more talent and new investment moving to the locality to set up a business. In contrast to the firms servicing the local economy, the firms on the traded side of the economy are free to choose their location.

From an economic development perspective, the evidence is now clear that the stronger the cluster is, the more high value jobs are generated. Employment growth will tend to be stronger where companies are not limited to servicing the local market, i.e. the traded side of the local economy. The firms on this traded side of the local economy also tend to pay higher wages and more local taxes.

Summarising, there is a clear and positive link between cluster development and:

- Innovation

- Productivity

- Competitiveness

- Job creation

- SME growth, new firm survival

- Investment attraction and high value migrant attraction

- Export development

The European Union views clusters as: 'A key source of competitive advantage in the global economy' and 'Underlines the importance of strong regions in modern economic policy.' It therefore comes as no surprise that the EU is actively supporting cooperation across Europe of regional 'research-driven clusters' with the overarching objective of promoting European competitiveness and regional development through the smart specialisations of regions in a globalized world.

The logic for this approach centers on:

- The positive links between clusters, productivity and competitiveness

- Regional economies develop through their clusters

- Clusters enable places to connect to the global economy

- Clusters develop and attract public and private resources and provide a practical framework for policy development

- Clusters foster interaction and collaboration amongst firms

- Clusters provide impetus and direction for innovative activities 


\section{Special Contribution}

- Increasing efficiencies come with co-location, in particular a specialised labour force.

- Related diversification, with new clusters emerging from existing ones.

\section{Clusters and Public Interventions}

Clusters are becoming an increasingly popular concept, which is reflected in a growing number of policies and initiatives in support of clusters (CEC 2008). The EU's January 2008 report on 'Cluster Policy in Europe' identified that all European countries had in place cluster programmes on a national and/or regional level. As the UK's Department of Industry has summarised:

'Enterprise clusters and networks are recognised as important settings for the development and growth of SMEs because they help improve productivity, increase innovation capability, facilitate the commercialisation of innovation and generate high employment. At a bigher level, clusters and networks enhance the economic as well as the social growth of the region or nation hosting them'

'Research suggests that clusters of firms and skilled workers may be one of the key drivers of economic growth in localities, cities and regions.'

During the last decade cluster-based economic development has become an increasingly common focus, with over 75 countries now having cluster development programmes in place. As well as national and regional economic development agencies, the World Bank, UNIDO and many international aid agencies, including USAID and Swedish AID, are sponsoring cluster interventions. These interventions go well beyond analysis to building engagement and action within each cluster.

Clustering efforts around the world have been particularly successful at the local/regional level, where effective collaboration between the private and public sectors has resulted in upgrading the competitiveness and reach of the cluster.

\section{Defining 'Clusters'}

At its simplest level, a cluster is a group of firms that are operating in the same sector and are in close geographical proximity to each other. A cluster may also have a range of support organisations such as trade associations, chambers of commerce, technical and training institutes, government agencies, universities and schools. A cluster is therefore more than just a group of firms. There may (or there may not) be close relationships between these different players.

While there are many definitions of 'clusters,' all share the relevance of geographic proximity, networking and specialisation. Common characteristics also include networking and collaboration amongst the cluster's players. The definitions that follow start to explore what is going on inside a cluster.

'Geographic concentrations of interconnected companies, specialised suppliers, service providers, firms in related industries and associated institutions... in particular fields that compete but also cooperate.'(Porter 2000)

'A cluster is an alternative way of organising the value chain. Compared with market transactions among dispersed and random buyers and sellers, the proximity of companies and institutions in one location and the repeated exchanges among them - fosters better coordination and trust. ... A cluster of independent and informally linked companies and institutions represents a robust organisational form that offers advantages in efficiency, effectiveness and flexibility.' (Porter 2000)

'Groups of related businesses in a common geographical framework, operating in an environment characterised by a high level of specialisation, intense competition and a critical mass of highly-trained employees.' World Economic Forum

Sectoral and geographic concentrations of enterprises that produce and sell a range of related or complementary products and, thus, faces common challenges and opportunities.' UNIDO

'A concentration of enterprises producing same or similar products or strategic services and is situated within a contiguous geographical area spanning over a few villages, a town or a city and its surrounding areas in a district and face common opportunities and threats.' Indian Cluster Observatory

'A concentration of 'interdependent' firms within the same or adjacent industrial sectors in a small geographic area.' European Union ${ }^{3}$

$\overline{3}$ http://ec.europa.eu/enterprise/enterprise_policy/analysis/doc/smes_observatory_2002_report3_en.pdf 
'Groupings of independent undertakings - innovative start-ups, small, medium and large undertakings as well as research organisations - operating in a particular sector and region and designed to stimulate innovative activity by promoting intensive interactions, sharing of facilities and exchange of knowledge and expertise and by contributing effectively to technology transfer, networking and information dissemination among the undertakings of the cluster.' EU's Community framework for State Aid for Research and Development $^{4}$

'Groups of firms in the same or related industries whose development is interdependent.' (Enright 2011)

The phenomenon of clusters has been well described by Professor Michael E. Porter, the OECD and many others. It is increasingly clear that, faced with the opportunities (and the challenges) of globalisation, a number of localities around the world, sometimes small, are developing a particularly innovative environment in a specialised area and through extreme competitiveness establishing a global reach. As a direct result these communities have wealth generating capabilities well beyond many other localities in their country.

\section{Wannabe Clusters}

Most of the cluster development initiatives underway around the world are well grounded in the reality of their local communities, systematically building on the local strengths. But some clustering initiatives are more vulnerable 'want-to-be' clusters, in many cases driven by local politician's wish lists. ICT, biotech, nanotech and creative activities are particularly popular 'wannabe' clusters.

Drawing on the example of Silicon Valley, an extensive (and without doubt excessive) number of 'Silicon Somewhere's' are under development. The evidence from around the world is quite clear: it is very difficult to create a new cluster. Many of the Silicon Valley imitators will be unsuccessful. Cluster development is not about creating clusters or picking winners, but rather fundamentally understanding and then building on a region's strengths, the smart specialisations.

\section{What is not a Cluster?}

As the term 'cluster' has become increasingly popular, the term has become over used. So what is not a cluster?

- A real estate development, such as an industry estate, a science or technology park, a precinct;

- An export processing zone; a special economic zone; a free trade zone;

- A business incubator for start-ups;

- An industry, a trade or a professional association;

- A consortium between a number of firms;

- A grower's cooperative;

- A business network; an alliance between firms.

But each of these may well be an important element within a cluster. The knowledge infrastructure and the social connections are typically more critical than the physical infrastructure. Co-location does not automatically lead to connectivity.

The geography of a cluster, its functional region, is usually broader than that of an industry park. The spread of competencies within a cluster is usually more specialised and narrower that those found on an industry park, or even a 'science/technology park.'

A cluster is neither 'a sector' nor 'an industry.' A cluster can involve elements from a variety of sectors or industries: for example a furniture cluster can include the forestry industry as well as wood processing, metal componentry, packaging, transport and the finance sector.

A 'value chain' may well be a component within a cluster. Clusters are broader than a value chain and include any organisation that has impact on the cluster. Value chain development has a narrower focus and is more transaction orientated. Clusters are geographically centered while value chains may span multiple regions. A value chain approach is typically linear; a cluster development approach more systemic. Value chain analysis is one of several tools that can be used in understanding a cluster's competitiveness; value chain development is an important component in upgrading the competitiveness of many clusters.

\section{Clusters in Decline}

No cluster has a locked-in permanent competitive position in perpetuity. Clusters can fossilise over time as their competitive position is eroded. As the intensity of global competition develops further, clusters will fall (and rise) more rapidly. Here are examples of clusters that have grown to leading

${ }^{4}$ Europe INNOVA /PRO INNO Europe Paper No 9, 2008. 


\section{Special Contribution}

positions, then withered and in some cased totally disappeared. Sometimes all that is left behind is a museum as a memento of past glories.

As early as the thirteenth century Worcester, England had a Glovemakers Street and by 1820 glove manufacturing had grown to dominate the local economy and employ 30,000 people. Worcester remained until the 1950 s the world's major glove manufacturing center (Wilson and Popp 2003);

Lancashire, England was a world leading textile centre; Belfast, Northern Ireland, the home of the Titanic, was a major shipbuilding center. At its height, Belfast had one of the biggest shipyards in the world.

Dundee, Scotland in the 19th century was known as 'Juteopolis', the main centre in the world for jute processing and jute machinery. Today Dundee is home to Scotland's Jute Museum.

Macclesfield, England was once the world's biggest producer of finished silk; today it is home to four silk museums.

Romans-sur-Isére is still recognised as the shoemaking capital of France though what largely remains of the once thriving leather and shoe cluster are discount shoe retailers and a shoe museum.

Medicine Hat, Alberta accounted for $75 \%$ of Canada's pottery production in the 1920's. Today all that is left is the Historic Clay District Museum.

Paul Krugman refers to the USA's 'bistories of the concentrations of underwear in Cohoes, costume jewelry in Providence, detachable collars and cuffs in Troy, gloves in Gloverville'(Krugman 2010). All are clusters that have long since died. 'Many of the industrial clusters of the past are pushing up the daisies, have gone to meet their maker, have become ex-clusters.'

Common elements in the decline of a cluster can include:

- A halting in the spin-off process with few new companies coming through; the cluster unable to attract fresh talent; a static group of firms; anchor firms and skilled labour exiting to more fertile environments; - Rigid specialisations and internal inflexibilities that weaken firm innovation and productivity improvements; the development of cartels and mergers that reduce local rivalry; union inflexibility;

- A collective myopia within the cluster, unable to see how the future is changing, institutional sclerosis developing; unable to develop new business practices, locking in to old solutions, old technologies, old markets;

- Privileged tacit information being available to only a few members of an 'old boys club' within the cluster, a senior group that is more comfortable in maintaining the status quo than in going through the pain of change;

- New centers emerging in other regions with lower cost structures; new technologies developing and/or markets changing with evolving buyer needs and the cluster unable to adapt in time; major changes in demand.

\section{The Case against Clusters}

Amongst academics and to a lesser extent amongst economic development practioners views are expressed on the irrelevance of local clusters in today's global environment and arguments made against cluster development interventions.

Some academics interpret 'cluster development' as creating clusters and should rightly be concerned about such a naive approach. The dangers of over specialisation within a region are highlighted by other academics, along with the danger of public subsidies being used to artificially extend the life of a decaying cluster. The risks of politicians determining in isolation a cluster's development agenda are also highlighted. However, each of these valid concerns can be addressed through careful management of the cluster development process.

Academics have also highlighted the lack of precision over what exactly constitutes a 'cluster.' There is a similar imprecision over what constitutes a 'city.' Cities come in all shapes and sizes, as do clusters. Cities often have blurred geographic boundaries, as do clusters. There is no single definition of a 'cluster' that will cover all analytic needs.

In reality clusters exist and are visible across all countries and sectors. Geographic proximity is even more important today, in particular for knowledge intensive clusters. Tacit information and knowledge move through face-to-face contact. The availability of Skype and other communication tools certainly accelerates the movement of codified knowledge

${ }^{5}$ Martin \& Sunley make a strong case against clusters, recommending that economic developers should focus on improving the general business environment. 
and supports a cluster in connecting with customers and others beyond the cluster's region, but innovation, as can be seen in Silicon Valley, remains very sticky to a place. Local clusters are an increasing reality in today's globalised world.

\section{Specialisation v. Diversification}

The focus for cluster development is at a regional/local level, not national. An important question is should a region's economic development strategy be centered on specialisation or diversification? The arguments continue between economic development practitioners and amongst academics on the merits of focussing on existing industry concentrations or alternatively developing a broader base of economic activities within a region.

Certainly an over dominance on a single economic activity can be risky in today's global environment. Over specialisation presents the danger of a new competitor suddenly emerging or the risk of myopia and lock-in with isolation from changing markets and technologies. It can also limit the opportunities for the absorption of new knowledge from other activities within a community. On the other hand, a regional economy that is still a 'ittle bit of everything' is most unlikely to be internationally competitive with many of its offerings.

Political leaders may well be seeking an economy composed of a series of specialised (and linked) high growth clusters. Succeeding with such a broad ambition is in part dependent on the size of the local economy.

In reality, a region has few opportunities to change its economic structure and the limited public resources that are available to support economic development need to be focussed. A smart option in applying these resources is to build on the region's specialisations, its clusters.

A second economic development option is broader: fostering an entrepreneurial environment that supports new business start-ups and growth such as through firm mentoring and an angel support network. The entrepreneurs being supported will be seeking high growth opportunities and these are likely to come from servicing a wider market than the region itself. Such opportunities will tend to be found within the region's clusters. And innovative clusters, with an array of supporting firms and a specialised soft infrastructure, provide a particularly fertile environment for business growth.

Successful entrepreneurs will be pushing out the boundaries of those clusters, developing new products and services, applying new technologies and exploring new markets. And by developing these opportunities at the periphery of their clusters, they will be broadening out and diversifying their region's wealth creating base.

Sustainable diversification particularly comes from building and extending a region's strengths, the clusters. It is unlikely to come from a random scattering of activities. And this related diversification may well lead to the emergence of a new cluster, such as the historic textiles cluster in Saint-Etienne, France developing firstly medical textiles competencies and then a broadening out to a medical technology cluster. Similarly new economic activities have developed around the San Diego, California bioscience cluster, centered on pharmaceuticals and medical devices.

Specialisation comes first; then comes diversification. These are both valid routes to cluster development and to economic development.

\section{Supporting Quotations}

Navi Radjou, University of Cambridge

'What R\&D theory shows is that the best way you can seed innovation is if all the stakeholders are in the same place.

Having co-location of the different stakeholders accelerates knowledge-sharing and development of new products and services in a way that you can't do if they're scattered.'(Economist Intelligence Unit 2011)

\section{UNIDO}

'The cluster concept has gained prominence as an economic policy tool aimed to foster innovation and the growth of a competitive private sector in developing countries.'

Cluster development for pro-poor growth: The UNIDO approach (UNIDO 2010)

\section{Professor Richard Florida}

'In today's creative economy, the real source of economic growth comes from the clustering and concentration of talented and productive people.'

Who's Your City (Florida 2008)

\section{Paul Krugman}

Quoting an Apple executive:

You need a thousand rubber gaskets? That's the factory next door. You need a million screws? That factory is a block away.'

'The point is that successful companies don't exist in 


\section{Special Contribution}

isolation. Prosperity depends on the synergy between companies, on the cluster, not the individual entrepreneur.'

New York Times, 26 January 2012 (Krugman 2012)

The World Bank

'The Special Economic Zones and industrial clusters have made crucial contributions to China's economic success.'

Douglas Zhihua Zeng (Zeng 2011)

Asian Development Bank

'Successful cities increasingly foster growth in high value added industry clusters using skilled workers, advanced infrastructure and innovation.'

Competitive Cities(Choe and Robert 2011)

Vienna Cluster Manifesto 2012

'Clusters are particularly important for implementing research and innovation strategies for smart specialisation taking into account the different needs and priorities of the regions.' (Vienna cluster manifesto 2012)

\section{CLUSTERS: AN INTERNAL PERSPECTIVE}

There is no single blue print for successful clusters. Each cluster evolves in its own way. However, there are a number of common aspects within strong clusters that are identified in this second chapter. These aspects start to outline the direction for a successful clustering intervention.

\section{Common Features of Strong Clusters}

The generalisations that follow draw on the features of a wide range of innovative clusters across many sectors. I have had the opportunity to be exposed to over 1,000 clusters globally, covering a diversity of countries and environments. Some of these clusters are struggling; others are dynamic with the competitiveness of their firms continuing to develop. As is highlighted, a strong cluster is not an agglomeration of separate, isolated enterprises but a dynamic system with a dense and close web of inter-relationships.

The cluster's culture. The processes of creativity and innovation are the result of face-to-face discussions. The success of an innovative cluster is in a large part due to the participants within the cluster forming quality personal relationships. These links are particularly informal and are supported by more formal organisations, institutions and strategic alliances. Existing relationships within the community coupled with norms of trust and reciprocity contribute to the building of social capital.

Within a strong cluster there is both strong rivalry and intense competition between firms. This is central to fostering innovation. The geographic and social proximity facilitates collaboration alongside competition. It is not a question of one or the other, but simultaneously both...a culture of coopetition.

A strong cluster does not have clumps of isolated firms but a dense network of inter-linked firms. Strong clusters have evolved more a networked form of production than a few large, vertically integrated firms. Firms within the cluster are flexible, adaptive and well connected with each other. Firms are able to co-specialise and to lift productivity through focussing on their core competencies, doing what they do best and then outsourcing and sub-contracting their non-critical activities locally.

The intensity and commitment to firm collaboration increases as trust develops. It is trust that lubricates any cluster, reducing transaction costs and opening information flows. This inter-firm collaboration may include:

- Joint product design; joint manufacturing; joint sales and marketing; the establishment of export consortia; jointly servicing common customers

- Soft, informal networks (e.g. for joint purchasing) and hard, more formalised networks (e.g. strategic alliances for joint off-shore investments)

- The tighter alignment of vocational training and public R\&D around the specific needs of the firms.

There are well-developed and open communications across the cluster. This provides the cohesion and assists in responding to abrupt changes that can arise in the cluster's competitive environment. The close interaction and high frequency of exchanges between co-located firms underpins competition and also stimulates innovation. A sense of belonging is created that helps with the alignment of activities. This also speeds up the innovation process.

Eyeballing not E-mailing. Much has been written about the death of distance and the rise of virtual clusters, but eyeballing still remains the key to an innovative milieu, not emailing. In spite of revolutions in communications and transport, proximity matters more than ever for knowledge 
intensive activities that need face-to-face conversations. 'Knowledge crosses corridors and streets more easily than oceans and continents'(Feldman 1994).

Geographic and social proximity facilitates a common behaviour code amongst the cluste's stakeholders, a common language and a common understanding of the competitive dynamics of the cluster. This proximity builds momentum to jointly engage in addressing common issues and opportunities.

Cisco, a developer of collaborative technologies, boldly refer to 'geography fading into virtual territories' with the advent of new communication and collaboration technologies such as their WebEx(Lange et al 2010). Certainly many clusters have yet to fully exploit the new opportunities that are opening up through the digital economy, opportunities that facilitate cluster-to-cluster links globally and enable firms to more easily service global customers. Distance is not the problem it used to be.

But where is Cisco's own innovation hub and head office? It is in Silicon Valley along with Adobe, Apple, eBay, Facebook, Google, Hewlett-Packard, Intel, LinkedIn, National Semiconductor, Oracle, SanDisk, Yahoo! and 7,000 other high tech firms. As Cisco point out in their White Paper, average incomes in the Valley continue to grow faster than the US average, evidence that Silicon Valley is becoming even stronger. If proximity ceases to be a critical ingredient in an innovation system, then Silicon Valley will be one of the first places in the world to implode. There is no sign of this yet.

In an increasingly globalised world the 'local' is becoming more important, not less important, especially for knowledge-intensive activities. New economy business practices are collaborative, built on trust, dialogue and alignment and this is facilitated through co-location.

Tacit information flows. There is rapid movement of high value knowledge that is based on close personal relationships and frequent face-to-face interactions. This tacit knowledge is the knowledge that is 'in the air', it has yet to be codified and written down; it is hard, at times impossible, to transmit tacit electronically. It is often very specific, complex and cumulative in its development. It is sticky to a place.

Sharing a common coffee pot, chance meetings and the informal, spontaneous discussions remain much more important for tacit information flows than occasional conference gatherings, pre-arranged meetings, Twittering and emails. Tacit knowledge moves through informal conversations, net- working between firms and through engagement on joint projects, through training programmes, through labour mobility as people change jobs within the cluster and through firm spin-offs and new start-ups. As trust improves the circulation of tacit knowledge increases.

By contrast, codified knowledge such as operating manuals, blueprints, procedures and patents is explicit; it can be stored and written down... and therefore it is immediately global in distribution, and equally accessible from anywhere in the world. The world is indeed flat when it comes to the transmission of codified information.

Whilst e-commerce is increasingly underpinning cluster activities and Skype, Facebook and Twitter are becoming common cluster communication tools, these are no substitute for direct face-to-face communications, the physical eyeballing. The movement of codified information is facilitated by e-mail; the movement of the higher value tacit information is dependent on trust, proximity and eyeballing. Tacit information is sticky to a place.

Geographic proximity of firms. The close geographic proximity of firms and organisations promotes the rapid circulation of tacit knowledge and the easy movement of sub-components and finished products. Proximity permits a higher level of networking, both commercial and social, promoting greater trust. This high level of trust makes co-operation and joint action easier and more likely, allowing firms to work together to develop common opportunities and to solve common problems. Geographic proximity facilitates firm collaboration, out sourcing and co-specialisation.

An innovative environment. An environment that facilitates the development of new products, new processes and new business models underpins a strong cluster. New combinations that draw on a range of competencies and firms from within the cluster enable new solutions to be developed. The close proximity of competitors drives the pressure to innovate. New concepts and new technologies have difficulty remaining hidden when tacit knowledge is flowing.

New firm formation. Clusters provide a lower risk environment for new firms entering the cluster as there is access to pre existing customers and supply chains and skilled labour and info flows... There are strong regional networks that are founded on trust, drawing together firms, universities and research centers. These networks speed up the innovation process. An innovative cluster provides a fertile environment 


\section{Special Contribution}

for the emergence of new firms. There is a low barrier to entry for new firms, with spinoffs emerging from larger firms within the cluster and local institutions. The supportive growth environment for new start ups is fostered by the local tacit information flows coupled with the availability of skilled staff and specialist suppliers, including well informed banks who understand the commercial risks facing start-ups. These firms continually extend the product range and therefore the reach of the cluster.

A self-reinforcing cycle develops within the cluster with spin-offs from the original leader and anchor firms and these successful entrepreneurs over time become mentors and financial angels for the next generation of firms, thus continually fuelling the growth of the cluster.

Clusters are beneficial to both large and small firms. Clustering provides economies of scale and scope that enable small and medium sized enterprises (SMEs) to tackle issues that would be impossible to address in isolation. The dynamics of the cluster allow them to compete with much larger firms both at home and abroad. Large firms act as important partners and customers for SMEs. Large firms benefit from SMEs that are experimenting at the cluster's periphery, exploring new products, new markets and new technologies.

Aligned support. There is well coordinated and aligned support for the cluster from a wide range of public organisations (and where relevant NGOs), each operating within their own silo but offering a co-ordinated support based on a common understanding of the cluster's needs. There is open dialogue that facilitates the development of targeted and wellfocussed investments by public agencies...a realisation that precision is more important than the volume of public investments; i.e. not a clutter of uncoordinated public agencies. ${ }^{6}$ Government policies and regulations are aligned with the clusters needs.

Specialisation. Specialised core firms; specialised support firms; and specialised soft infrastructure institutions. Specialisation is rampant. Taken together, these provide a concentration of specialised knowledge and information. Over time this specialisation can develop into a world leading position within a niche area.

Building the knowledge infrastructure. There is clear focus on developing the (more complex) soft knowledge infrastructure and the social connectivity rather than the (relatively easy) hard physical infrastructure.

Availability of skilled workforce. A skilled and adaptable workforce is an essential ingredient in a strong cluster. A successful cluster is able to both grow its own workforce and attract talent to the region.

Testing home market. The availability of a dynamic home market that provides easy access to demanding customers who keep placing additional pressure on their suppliers is a key. The local environment facilitates the rapid development and testing of new products/new services with tight feedback loops. The nature of this local market is much more important than its size.

External links. There are strong and extensive external links with a multiplicity of pipelines. Connections with the world beyond the cluster are not in a few hands. Strong and weak ties are connecting firms to the outside world as well as connecting academic institutions, training organisations etc. These links enable rapid internalisation and adaptation to meet the needs of international customers.

New technologies. Innovations are quickly being assimilated; knowledge is shared and integrated across the public and private sectors. There are ongoing, tight relationships between firms and support institutions, especially universities and public R\&D institutions. The flow of information is twoway enabling technology development and knowledge transfers from publically funded organisations (R \& D centers, universities) to be needs driven. Local universities and training institutions focus on meeting the skilled labour needs of the local firms.

Access to finance. Equity, venture capital, debt financing and specialised financial advice are available as an economic foundation for the cluster.

A magnet. An innovative cluster is a magnet, often on a

\footnotetext{
${ }^{6}$ In the USA in 2006, fourteen different federal agencies had 250 separate programmes of relevance to regional economic development. The agency silos offering small business assistance, workforce training and R \& D in the USA are highlighted in 'Blueprint for America's Prosperity' on 'Clusters and Competitiveness' prepared by the US Brookings Institute, Washington DC. In addition are a multiplicity of state and more local agencies with a role in economic development.

${ }^{7}$ Technology incubation mechanisms such as incubators, innovation centers and science parks have their place but success has been mixed in many countries due to an over focus on the hard infrastructure and an under focus on the soft infrastructure.
} 
world scale, attracting new customers, attracting premium foreign direct investment (rather than branch plants ${ }^{8}$ ), attracting talent to the cluster (migrants, entrepreneurs and students), attracting new knowledge (including links with lead institutions globally) and attracting supportive and specialised public investments. ${ }^{9}$ While branch plants are welcomed by the cluster, 'quality investments' includes firms that broaden out the cluster's competencies, fill a gap in the support business capabilities, add to the cluster's R\&D activities, or provide access to new markets.

High quality inward investment raises the international profile of the cluster, demonstrating the cluster's attractiveness and enhances the profiles of the existing firms. Once established, foreign firms can contribute to the cluster's ongoing upgrading. Such quality investments are embedded within the cluster through the establishment of local supply chains and local training facilities.

Institutions for collaboration. A wide range of partnership organisations are in place spanning the boundaries amongst firms and between firms and support institutions; promoting networking and collaboration amongst the local actors; championing the cluster within the region and beyond; encouraging purposeful collaboration and ongoing collaboration in the key areas of common interest; and supporting project teams engaged in collaborative projects. These partnership organisations are complementary to, rather than competing with, established industry associations.

Physical infrastructure. For example, land for industrial development, transport infrastructure, fiber-optic cables, and waste management services.

\section{Segmenting Innovative Clusters}

Four broad categories of firms and institutions can be identified within many innovative, high performance clusters:

- The core firms that through servicing more distant customers are attracting wealth to a region;

- The support firms;

- The soft, social infrastructure; and

- The hard, physical infrastructure.

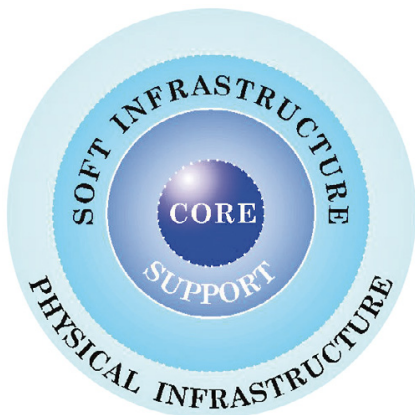

(c) Cluster Navigators Ltd

\section{A. Core Firms}

Core firms can range from large multinationals to small and medium enterprises (SMEs), start-ups, spin-offs and informal firms. Some clusters are centered on a few anchor firms that over time lead to the emergence of supplier firms. Other clusters have a large number of SMEs.

The firms that are at the core of an innovative cluster will have developed the competitiveness to obtain some of their revenues from customers who are located beyond the cluster's functional region. These core businesses are not totally dependent on local customers. They are attracting wealth into their home community.

Core firms within a strong cluster are well connected both within the cluster and beyond. These firms often develop strong backward links to related and supporting firms within their cluster; they are also well connected with external markets, with strong forward links, often to global value chains. They are well aware of market and technology changes.

These firms don't try to innovate in isolation. Over time a system of co-specialisation evolves amongst the core firms based on an appreciation that not every firm has to do everything. This understanding, centered on trust, enables even competitors to engage with each other in non-threatening areas. Core firms may be participating in collaborative structures such as consortiums, learning networks, or cooperatives.

A number of common aspects can be seen amongst the core firms in strong, innovative clusters:

\footnotetext{
${ }^{8}$ The attraction of branch plants is not seen as a key to the development of the local economy: branch plants tend to be production dominated often with an assembly line process, have limited R \& D capacity, limited local purchasing capability and low value added. Their managers often have limited autonomy to engage in local collaborative activities.

${ }^{9}$ And in less developed economies attracting support from multilateral agencies, donors and NGOs.
} 


\section{Special Contribution}

- Dense networks of inter-linked, entrepreneurial firms. Anchor firms are integrated into the cluster. - Strong backwards links and forwards links, often to global value chains. Firms well connected to external markets.

- Well-differentiated, highly specialised firms focussing on their core competencies and pushing out into new activities.

- Interconnected firms with a multiplicity of informal and formal links between them; similar norms and attitudes, a common 'language.'

- Strong rivalry between firms centered on differentiation with distinctive strategies, not price;

- But also inter firm collaboration, a culture of co-opetition with simultaneous collaboration \& competition; firms collaborating to reduce input costs, to add value and the intensity of collaboration increasing with trust.

- Multinationals embedded in the region, drawing on the region's knowledge, investing in $\mathrm{R} \& \mathrm{D}$, relocating key activities to the region.

- Out-sourcing to local firms of non-core activities.

- A demanding home market continually placing pressure on suppliers.

- Large firms nurturing SMEs as specialist suppliers, acting as an incubator for spin-offs.

- Continual increase in the number of firms, spawning of new firms, high churn rate with the creation and renewal of firms. Anchor employees establishing their own firms.

- Inward migration of technical and entrepreneurial talent.

\section{B. Support Businesses}

These are the businesses that are directly or indirectly supporting the businesses at the core of the cluster. The support businesses may include, depending on the cluster's activity, a range of suppliers:

- Raw material suppliers,

- Machinery suppliers,

- Component suppliers and

- Packaging suppliers.

'Support businesses' also includes a wide range of service suppliers and these firms are often very specialised, for example:

- Banks and other providers of debt and equity finance, including seed funders, angel finance, providers of venture capital and investment banks specialising in IPOs;

- Accountancy practices that are familiar with the particular needs of the cluster's firms;

- Payroll management services;

- Technical service firms, testing, prototyping;

- Transport, logistic and storage services; air services

- Legal firms with specialist capabilities handling IP issues and technology transfer;

- PR and marketing specialists;

- Executive search firms, recruitment agencies;

- Management, design, market research, marketing and technology consultants.

Common aspects amongst the support firms within strong clusters can include:

- Deep specialisation and with the specialisation high productivity.

- Close and open interaction with the cluster's core firms based on trust... co-developing, co-producing and innovative. Long-term relationships rather than ad-hoc transactions, rapid flows of tacit knowledge.

- Capability gaps identified and filled by targeted firm and talent attraction.

- Efficient transport logistics, the availability of airline connections and financial intermediaries in place.

- Mentor support and seed funding available for high growth support firms.

- Over time as their competencies grow the support firms may develop the capabilities to profitably service more distant customers and become the nucleus of an emerging cluster.

\section{Soft, Social Infrastructure}

In an innovative cluster, the businesses at the core and the support business are not working in isolation from their broader community. They are part of a local, supportive, eco-system.

The qualities of this soft infrastructure and the extent of effective teamwork within it are central levers in the development of any cluster, enhancing knowledge flows and spill overs. The services provided by the support organisations have a direct influence on the ability of core firms to compete internationally and to link into global value chains. This soft infrastructure is especially critical for knowledge-intensive clusters, broadening access to information and making avail- 
able services and initiatives (an institutional thickening) that continually upgrades the cluster's competitiveness.

Successful clusters have the active involvement of a broad range of actors within the soft (social) infrastructure, often including:

- Relevant economic development agencies and regulatory agencies from national, provincial/state and local levels, which could include Treasury/Finance, Industry, Education, Trade, Foreign Affairs, Investment Attraction, Science \& Technology, Women's Affairs, Regional/Rural Development, Transport...

- Universities, other tertiary institutions, technical training and vocational organisations, local schools, alumni associations;

- R \& D institutions, technology transfer organisations, prototype testing and analytic laboratories;

- Standard setting organisations;

- Trade and professional associations, think tanks;

- Trade unions;

- Business and industry associations ${ }^{10}$;

- Chambers of commerce and other private sector groups;

- Local mayors, politicians;

- Angel and mentor support groups;

- In some countries, multilateral agencies, donors and NGOs.

The intermediary entities such as industry associations and technology transfer organisations can be viewed as Institutions for Collaboration (IFCs) that collectively enhance the connections and the movement of tacit information within the cluster.

For a cluster seeking to be the dominant player on a global scale, the quality, specialisation and connectivity within the soft infrastructure needs to more than match the world's best.

Common aspects within strong clusters amongst the soft infrastructure organisations can include:

- Well-coordinated and aligned public support that is centered on the needs of firms.

- Public agencies able to listen to and respond to the needs of groups of firms as the needs emerge. Public support for groups of firms, not individual firms, with stability in the support being offered.

- Public support centered on the already strong and dynamic clusters, not the ambulance cases. Alignment amongst public agencies around the needs of the cluster, not a clutter of support. Effective dialogue and trust amongst the agencies, not competition.

- Close interaction between academic institutions and businesses; porous boundaries with ideas and people circulating.

- Universities undertaking pre-competitive, needs driven, research; designing courses in collaboration with firms; able to support the commercialisation of promising innovations; seed funding for new ventures.

- High schools offering specialised courses.

- Technical training agendas developed through partnerships with firms.

- A self-help cluster association in place with a focus on upgrading competitiveness, 'strategic doing'. Such an association is complementary to any industry association or Chamber of Commerce.

- A proactive, professional, cluster facilitation team in place underpinned with long-term funding.

\section{Hard, Physical Infrastructure}

The final element in characterising a cluster is the hard physical infrastructure. The nature of a cluster's hard infrastructure will depend on the cluster's activity and maturity, but can include:

- Industrial land for development;

- Transportation links...roads, rail lines, ports, airports; inter modal logistic hubs;

- Communication links, bandwidth;

- Fresh water, waste treatment, waste management services;

- Industry/science/technology parks, precincts and incubators are usually placed in this 'hard infrastructure' category as the focus is typically more on real estate development than knowledge interactions and linkages.

The quality of the hard, physical infrastructure needs to at least match competitive clusters, be they local or further afield. Common aspects of the hard infrastructure within strong clusters can include:

\footnotetext{
10 An industry association may be representing a number of firms within a cluster but is unlikely to represent all the core \& support firms and the soft infrastructure organisations. In many parts of the world, industry associations focus on lobbying public agencies, on networking and on the provision of basic services to their members rather than positioning themselves as self-help coordination mechanisms with a wider role.
} 


\section{Special Contribution}

- Ready availability of serviced land.

- Decentralised administration, local decision making on e.g. land use.

- Where a cluster's function area extends over a number of municipalities, the municipalities are able to collaborate and avoid facility duplication.

- Specialised, dedicated physical infrastructure in place.

- Science parks that have a cluster focus, not multipurpose real estate developments. Local leaders appreciate that an industry park may be just a component within a cluster.

- Specialised incubators are co-located with specialised knowledge centers such as at a university.

\section{A strong cluster's culture}

Summarising the culture and attitudes of a strong cluster, common aspects often include:

- Extensive personal connections, frequent face-toface meetings; a high trust environment that enables the easy circulation of tacit information; spill over effects.

- Strong links (1) within the cluster, (2) with neighbouring clusters as part of the regional innovation system and (3) to related clusters internationally.

- A clear strategic focus: not a series of short term ad hoc projects that are top-down driven, but a co-ordinated strategy in place to take the cluster towards a preferred future that is bottom-up driven.

- 'Hot spots' within the cluster are clearly identified.

- A dedicated cluster development organisation is in place with professional cluster management and long term funding for the organisation locked in.'

- A culture of learning-by-doing rather than paralysis-byanalysis, action rather than yet more report writing.

\section{Clusters as Elements in a Local System}

A strong cluster is unlikely to be the sole cluster within a region. Strength comes in part with the geographic proximity of related clusters that together make up the regional innovation system. Most regions have a portfolio of clusters, with some firms being linked to two, even three, clusters and drawing knowledge and contacts from each. New clusters such as green tech often emerge where existing clusters converge creating a platform for new opportunities.

Many large cities have half a dozen clusters of significance.
London, for example, has banking, finance and insurance (densely clustered in the City of London), logistics, education, jewellers in Hatton Gardens, antique dealers (in Notting Hill) and auctions houses (in the West End) with media and creative businesses based in Soho.

Chiang Mai, northern Thailand's main centre, is a tourism hub servicing a regional population of 1 million. Related to tourism are a handicrafts cluster (lacquer ware, wood, silver); a food and agricultural cluster (including cut flowers); a fashion cluster (apparel, leather products, jewellery) and a wellness cluster (health services, massage, spas, natural cosmetics). Morogoro, Tanzania (population 250,000) has a portfolio of clusters that includes horticulture, processed foods, rice and agricultural engineering. The Nelson region in New Zealand (population 85,000) is home to a seafood and aquaculture cluster, apples, tourism, wellness, aviation and engineering.

In each of these examples the local clusters are part of the wider regional innovation structure, with a multiplicity of links between businesses, academics and public agencies. The businesses within each cluster are not limited to the knowledge base that is created within each cluster.

\section{Industry Parks \& Incubators}

Many public agencies around the world are engaged with the development of industry parks and business incubators. Some agencies mistakenly view such developments as 'cluster development.' While neither an industry park nor an incubator is a cluster, both can be important aspects of a cluster's physical infrastructure. The physical co-location facilitates connections and face-to-face meetings, making it easier for firms to focus on their core competencies and then out source other activities and to generally reduce transaction costs.

However, physical proximity does not necessarily imply social proximity. Both are needed to create an environment where tacit information flows and a co-opetition culture are widespread. The real added value of industry parks and incubators lies in sharing know-how rather than sharing physical space.

Most industry parks (which may be given a more up-market label as a 'Science Park' or a 'Technology Park') and incubators have a limited role in enhancing entrepreneurship and contributing to regional development. Too often industry parks are isolated enclaves. The firms invited to be within an incubator or an industry park need to have commonalities of substance for the intervention to be particularly successful. This then enables a proactive focus on building the connections between the co- 
located firms, i.e. much more than real estate development.

When introduced, incubators and science parks should be considered as part of a broader economic strategy that is centered on the region's clusters. It is the commonalities amongst the business services offered by the incubator and industry park management that are the key to their success: specialised training; business advice that relates to the specificity of the cluster; and financial, legal and technology sup- overseas investors. Many have been particularly successful in attracting labour intensive activities. Not unsurprisingly, many special economic zones house clusters of related firms, though this is through evolution rather than design. The Antalya Free Trade Zone in Turkey happens to be by the sea and is now evolving into one of the Mediterranean's leading yacht-manufacturing clusters.

A European Commission report provides a valuable typolo-

Table 1. A typology of business incubators

\begin{tabular}{c|l|l|l|l}
\hline \multirow{2}{*}{$\begin{array}{c}\text { Management } \\
\text { support }\end{array}$} & & \multicolumn{1}{|c}{ Low } & \multicolumn{2}{c}{ Medium } \\
\cline { 2 - 5 } & Low & Industrial estate & Business park & Science park \\
\cline { 2 - 5 } & Medium & Managed workshop & Enterprise centre & Innovation centre \\
\cline { 2 - 5 } & High & Multipurpose business incubator & Business \& innovation centre & Technology centre \\
\hline
\end{tabular}

port that relates to the narrow needs of specialised tenants.

While incubators have a very tight geography and industry/science parks are part of a city or region, special economic zones have a much broader geography and can span a city (such as Shenzhen, China) or even a province. Special economic zones (sometimes called free trade zones, freeports, export processing zones, industry precincts or development corridors) are designated areas offering tax incentives and/or lower tariffs and streamlined customs procedures to attract gy of business incubators, linking the degree of technology specialisation with the level of management support ${ }^{11}$. Those incubators that have a high level of management support and a technology specialisation will be particularly valuable components within a cluster's eco-system.

\section{Cluster Differences}

Clusters come in a number of different forms. One means of differentiating clusters is by their life cycle stage:

Table 2. Cluster Differences by Life cycle stage

\begin{tabular}{|c|c|}
\hline Life cycle stage & Common characteristics \\
\hline Emerging & $\begin{array}{l}\text { - Start-up, pioneer firms sprouting; intuitive exploration; often recombining existing knowledge; uneven progress with false } \\
\text { starts then significant forward leaps; high isk; market uncertainty; seed finance, business angels; new product/service devel- } \\
\text { opment; evolving distribution hannels; strong patent activity. } \\
\text { - Cluster could be emerging at the periphery of an existing cluster, or through chance events; limited firm interaction \& link- } \\
\text { ages, more an agglomeration of firms, a clump; a clutter of support organisations with only partial awareness of the emerg- } \\
\text { ing cluster; importance of new knowledge development from centres such as a university. }\end{array}$ \\
\hline Growing & $\begin{array}{l}\text { - Cluster's competitive position may still be unclear; refining; attracting private investments, venture capital; attracting skilled } \\
\text { workers, talent; filling of competency gaps; merger and acquisition activity; an economic scale that now attracts public sup- } \\
\text { port; formation of non-market relationships facilitating tacit information flows; cluster self-organisation with collaborative } \\
\text { engagements underway; development of specialised support firms, institutions for collaboration, industry/cluster associations; } \\
\text { - Increasing trust \& interdependencies, informal collaboration; development of specialised suppliers \& services; co-specialisa- } \\
\text { tion; opening new markets; applying new technologies; product innovation. }\end{array}$ \\
\hline
\end{tabular}

\footnotetext{
${ }^{11}$ EC (2002) Benchmarking of Business Incubators, European Commission, Enterprise Directorate.
} 


\section{Special Contribution}

\begin{tabular}{l|l}
\hline \multicolumn{1}{c|}{ Life cycle stage } & \multicolumn{1}{c}{ Common characteristics } \\
\hline Maturing & $\begin{array}{l}\text { - Critical mass achieved; strong international reputation; well-understood competitive position; few and predictable risks with } \\
\text { small rewards; incremental and mainly in-house innovation; established networks \& institutions for collaboration; sub-groups } \\
\text { developing within the cluser. } \\
\text { - Profit pressures; sustainment, consolidation, fewer \& larger firms; innovation no longer at the forefront, fine tuning within the } \\
\text { currentknowledge base; data driven. }\end{array}$ \\
\hline $\begin{array}{l}\text { Declining } \\
\text { or }\end{array}$ & $\begin{array}{l}\text { Declining demand \& investment; stagnation, firm similarity, inability to adapt; mergers \& rationalisations; obsolescence; } \\
\text { exhaustion; predaory behaviours; erosion of social capital; firms shut down or depart for more favourable locations; decreas- } \\
\text { ing employment. } \\
\text { - New cluster(s) sprouting at the mature cluster's periphery; new products \& processes; a new knowledge stage. } \\
\text { New growth can be crisis or new technology driven; firm diversity, a spin-off renaissance offering renewal \& new growth } \\
\text { potential for the region. }\end{array}$ \\
\hline
\end{tabular}

Table 3. Further cluster typologies

\begin{tabular}{l|l}
\hline Marshallian clusters & - With many micro \& small firms, as in northern Italy \& across India \\
\hline Vertical clusters & $\begin{array}{l}\text { - Specialised division of labour within the cluster, difference stages in a supply chain links, for example: grape growers } \\
- \text { wineries - warehousing - transport - exporting }\end{array}$ \\
\hline Horizontal clusters & $\begin{array}{l}\text { - Common labour skills, technology \& capabilities applied to related industries in different sectors as in Silicon Valley; same } \\
\text { stage in the supply chain, for example: grape growers }\end{array}$ \\
\hline Hub \& Spokes & $\begin{array}{l}\text { - Centered on a few anchor firms that act as a magnet for supply firms. The supplying firms may then over time develop the } \\
\text { competitiveness to service more distant firms. } \\
\text { - Also used to describe a cluster with a geographic core (e.g. main regional city/urban) and outlying spokes (rural) }\end{array}$ \\
\hline Technology platforms & $\begin{array}{l}\text { - A platform of related technologies, such as agro-food, green energy, transportation or re-cycling, with a cross-fertilisation of } \\
\text { knowledge that traverses many boundaries. }\end{array}$ \\
\hline Satellite platforms & $\begin{array}{l}\text { - Centered on branch facilities } \\
\text { State anchored }\end{array}$ \\
\hline Sub cluster & - Centered around e.g. a defence facility, a public R\&D facility, a university, a public hospital \\
\hline
\end{tabular}

While clusters start naturally, the development of clusters does not need to be left to chance.

The origins of each cluster differ, but there are a number of common elements in facilitating their development. It is these common elements that are addressed in the Twelve Step cluster development process that I have introduced in cluster training workshops that have been held in over 45 countries around the world.

\section{Supporting Quotations}

Professor Michael E. Porter

'Geographic, cultural and institutional proximity provides companies with special access, closer relationships, better information, powerful incentives and other advantages that are difficult to tap from a distance. The more complex, knowledge-based and dynamic the world economy becomes, the more this is true. Competitive advantage lies increasingly in local things--knowledge, relationships and motivation--that distant rivals cannot replicate.'

Clusters and the New Economics of Competition(Porter 1998)

Margaret J. Wheatley

Innovation is fostered by information gathered from new connections; from insights gained by journeys into

12 Named after Alfred Marshall, highlighting a specialisation with many SMEs within a region. 
other disciplines or places; from active, collegial networks and fluid, open boundaries. Innovation arises from ongoing circles of exchange, where information is not just accumulated or stored, but created. Knowledge is generated anew from connections that weren't there before. '(Wheatley 1992)

Small Business Project, Johannesberg

'An innovative cluster is one where firms and others within a concentrated geographical area are co-operating towards common goals and establish close linkages and working alliances to improve their collective competitiveness.' Clusters as a Vehicle for SME Development: an alternative perspective(Small Business Project 1999)

World Bank's 'Clusters for Competitiveness' Guide

'The cluster-based approach offers a new way of dividing and understanding an economy and formulating policies and practices.'(PREM World Bank 2009)

Thor Sigfusson, Iceland Ocean Cluster

Icelanders tend to feel as they know everybody else on the small island and even though they don't know them, they can still give them a call. The problem with this attitude is that people are not making the call and if they don't, new ideas are not exchanged.

We arranged a meeting with over 20 CEO's of the high tech marine firms. The first thing we noted is that they began to introduce themselves to each other. Many had never met.'

Ocean Smart Workshop, Iceland, 2011(Sigfusson 2011)

Charles Darwin:

In the long history of humankind (and animal kind, too) those who learned to collaborate and improvise most effectively have prevailed.'

\section{REFERENCES}

Choe, K.A, and Roberts, B.(2011) Competitive Cities in the $21^{\text {st }}$ Century: Cluster-Based Local Economic Development. (Mandaluyong City, Phillippines : Asian Development Bank).

Cluster Development for Pro-Poor Growth : the UNIDO Approach(2010) available at http://www.unido.org/fileadmin/user media/Publications/Pub free/Cluster development for pro poor growth.pdf.

Commission of the European Communities (2008) The
Concept of clusters and cluster policies and their role for competitiveness and innovation : Main statistical results and lessons learned, Commission Staff Working Document SEC(2008) 2637(Brussels : European Commission).

Crocombe, G.T., Enright, M.J., and Porter, M.E.(1991) Upgrading Nerw Zealand's Competitive Advantage (Auckland, NY: Oxford University Press).

Economist Intelligence Unit(2011) Fostering innovationled clusters : A review of leading global practices $A$ report from the Economist Intelligence Unit, available online at http://www.managementthinking. eiu.com/sites/default/files/downloads/EIU-ATIC Report2 Web Revised.pdf(Enright 2011).

European Commission Enterprise Directorate-General(2002) Final Report : Benchmarking of Business Incubators (Brussels : European Commission Enterprise Directorate General) Available online at http://www.cses.co.uk/ upl/File/ Benchmarking-Business-Incubators-mainreport-Part-1.pdf.

Feldman, M.P.(1994) The Geography of Innovation. Economics of Science, Technology and Innovation Vol. 25 (Dordrecht : Kluwer Academic Publisher).

Florida, R.L.(2008) Who's your city? : how the creative economy is making where to live the most important decision of your life (New York : Basic Books).

Krugman, P.(2010) "The New Economic Geography, Now Middle-aged," prepared for presentation to the Association of American Geogrphers, April 16, 2010. Available online at http://www.princeton.edu/ pkrugman/aag.pdf.

Krugman, P.(2012) "Jobs, Jobs and Cars," January 26, 2012 The New York Times, Available online at http://www. nytimes.com/2012/01/27/opinion/krugman-jobs-jobsand-cars.html.

Lange, A., Handler, D., and Vila, J.(2010) Next-Generation Clusters : Creating Innovation Hubs to Boost Economic Growth, CISCO White Paper June 2010 (San Jose, CA: Cisco Internet Business Solutions Group).

Marshall, A.(1890) Principles of Economics (London : Macmillan).

Piore, M.J., and Sabel C.F.(1984) The second industrial divide : possibilities for prosperity (New York : Basic Books).

Porter, M. E.(1998) The Competitive Advantage of Nations 


\section{Special Contribution}

(New York : Free Press).

Porter, M.E.(1998) "Clusters and the New Economics of Competition," Harvard Business Review (Nov 01, 1998).

Porter, M. E. (2000) "Location, Competition, and Economic Development : Local Clusters in a Global Economy," Economic Development Quarterly 14(1): 15-34.

PREM The World Bank(2009) Clusters for Competitiveness ; $A$ Practical Guide \& Policy Implications for Developing Cluster Initiatives (Washington, DC : World Bank Institute), available online at http://siteresources.worldbank.org/INTRANETTRADE/Resources/cluster initiative pub web ver.pdf.

Schumpeter, J. A.(1982) The Theory of Economic Development: An Inquiry into Profits, Capital, Credit, Interest, and the Business Cycle (Social Science Classics Series) (New Brunswick, NJ : Transaction Publishers).

Sigfusson, T.(2011) How technology is driving the growth in the marine sector in Iceland, Ocean Smart Workshop in Ireland, July 5-6 2011, available online at http://www. ibr.hi.is/sites/files/ibr/Conference Ireland.pdf.

Small Business Project (1999) Clusters as a Vehicle for SME Development: an alternative perspective.

United Nations Industrial Development Organization (2010) Cluster Development for Pro-Poor Growth, the UNIDO Approach, Business, Investment and Technology Services Branch Technical Paper Series (Vienna : UNIDO).

Wilson, J.F., Popp, A.(Eds)(2003) Industrial clusters and regional business networks in England, 1750-1970, Modern economic and social history series (Burlington, VT : Ashgate).

Wheatley, M.J.(1992) Leadership and the New Science (San Francisco, CA: Berret-Koehler Publishers), 113.

Zeng, D.Z.(2011) How do special economic zones and industrial clusters drive China's rapid development? World Bank Policy Research Working Paper 5583 (Washington, DC : World Bank Institute) DOI: 10.1596/1813-9450-5583. 